\title{
MORALIDADES, RACIONALIDADES E POLÍTICAS SEXUAIS NO BRASIL CONTEMPORÂNEO
}

\author{
Sérgio Carrara
}

\section{Apresentação}

Ao revisar este artigo, já com preciosas sugestões editoriais em mãos, recebi o pedido de uma associação científica brasileira para colaborar, como antropólogo, na confecção de uma moção. Em foco estava o fato de diferentes câmaras legislativas do país, envolvidas com a aprovação de seus respectivos planos estaduais e municipais de educação, já estarem prontas a seguir o exemplo do Congresso Nacional que, em 2014, suprimiu do texto final do Plano Nacional de Educação (PNE) todos os trechos em que "gênero", "orientação sexual" e "sexualidade" eram explicitamente mencionados, fossem como fundamentos de desigualdades sociais e de práticas discriminatórias a serem "combatidas" nas e pelas escolas, fossem como temas importantes na formação de professores. ${ }^{1}$

Vinculada a diferentes denominações cristãs, a maioria dos deputados e senadores que se opõem a qualquer menção a questões relativas a gênero ou à sexualidade nesses documentos faz eco às manifestações públicas de diferentes igrejas evangélicas brasileiras e do próprio Vaticano quanto aos supostos perigos da disseminação, especialmente entre crianças e adolescentes, do que designam como "ideologia de gênero". Nas palavras de uma importante autoridade católica brasileira, segundo tal "sorrateira" "ideologia", "não existiria mais homem e mulher distintos segundo a natureza mas, ao contrário, só haveria um ser humano neutro ou indefinido que a sociedade - e não o próprio sujeito - faria ser homem ou mulher, segundo as funções que lhe oferece". A "ideologia de gênero", assim definida, seria "anticristã", "arbitrária" e "antinatural". ${ }^{2}$

Nesses termos, a crítica à "ideologia de gênero" reage tanto contra a difusão nas escolas brasileiras do ideal de igualdade entre homens e mulheres quanto contra o reconhecimento de que a diversidade de gênero e de orientação sexual ${ }^{3}$ deva merecer algum apreço ou respeito social, tendo 
direitos reconhecidos. Derrotados no plano nacional, militantes pelos direitos sexuais e reprodutivos, pela laicidade do Estado, feministas e ativistas LGBT, assim como diferentes setores da academia, como a associação que preparava a moção acima mencionada, mobilizam-se agora para evitar que a posição que se mostrou majoritária no Congresso Nacional "contamine" leis municipais e estaduais.

Do ponto de vista aqui desenvolvido, esse episódio deve ser considerado como mais um round no conflituoso processo de cidadanização ${ }^{4}$ de diferentes sujeitos sociais, cujas identidades articulam-se, seja na linguagem do gênero ("mulheres", "travestis", "transexuais femininos e masculinos"), seja na da sexualidade ou orientação sexual ("gays", "lésbicas" e "bissexuais"). Não sem reveses, tal processo se aprofunda atualmente no plano jurídico-político nacional e internacional. Para os mais diretamente engajados na "luta", em jogo estariam, de um lado, forças sociais "conservadoras", "retrógradas", "obscurantistas"; de outro, forças "progressistas", "libertárias", "esclarecidas". Abandonando estrategicamente tais dicotomias, parece-me mais produtivo abordar as atuais lutas por direitos civis e por proteção social empreendidas pelos ativismos LGBT e diferentes feminismos, assim como a progressiva incorporação de suas reivindicações pelos Estados nacionais, como portas de entrada privilegiadas para a análise de um processo muito mais amplo de transformação por que passa, no Ocidente, o próprio dispositivo da sexualidade, conforme concebido por Michel Foucault (1976).

Para tanto, o conceito de política sexual (Weeks 1989) é, por múltiplas razões, de enorme valia. Em primeiro lugar, possibilita a abordagem conjunta de diferentes tipos de ação social dirigidos ao Estado ou promovidos em seu âmbito ou sob sua chancela: legislações, campanhas sanitárias, programas educativos, normativas ministeriais, decisões judiciais, diferentes ativismos ou movimentos sociais etc. Em segundo lugar, permite a análise de processos sociais que se desenvolvem em múltiplos planos, pois, se as políticas sexuais vinculam-se historicamente a espaços sociopolíticos definidos pelas fronteiras dos Estados nacionais, tendo sido mesmo fundamentais para processos de construção da nação (nation bilding), elas têm sido forjadas cada vez mais intensamente no plano internacional e implementadas através de compromissos assumidos entre Estados, com a mediação de organizações que fazem parte do sistema das Nações Unidas (Vianna \& Lacerda 2004). Finalmente, torna possível discutir a natureza complexa e heterogênea dos modos de regulação das práticas erótico-sexuais e das expressões de gênero, uma vez que tais modos se consolidam a partir do enfrentamento ou da coalizão de diferentes atores ou forças sociais e refletem representações sociais de natureza muito diversa: ideias científicas, crenças religiosas, valores morais, princípios jurídi- 
cos, posições políticas etc. Nesse sentido, o conceito de política sexual permite interpelar simultaneamente múltiplas dimensões da gestão social do erótico e do sexual ${ }^{5}$ e explorar a coexistência, às vezes conflitiva, de distintos e muitas vezes contraditórios estilos de regulação moral, compreendidos aqui como conjuntos singulares de técnicas de produção de sujeitos, ou seja, de pessoas dotadas de certa concepção de si e de certa corporalidade. ${ }^{6}$

Porém, talvez mais importante seja o fato de que trabalhar no nível de tais políticas abre a possibilidade de abordar o próprio dispositivo da sexualidade, indagando sobre suas fissuras, tensões e horizontes de transformação, em suma, sua própria historicidade. ${ }^{7}$ Em tempos em que a sexualidade e o gênero são matéria para afirmação de direitos humanos, continuaria o célebre dispositivo a articular com a mesma precisão uma anatomopolítica dos corpos a uma biopolítica das populações? Ou estaríamos assistindo, em seu interior, à implantação de um novo regime da sexualidade? E, nesse caso, quais seriam suas principais linhas de força? Em que pontos haveria ruptura e em que pontos, continuidade?

É justamente para estas questões que me volto no presente artigo, esboçando uma ampla e tentativa hipótese interpretativa, relativa ao processo histórico de transformação por que passa contemporaneamente a sexualidade. Trata-se, como se vê, de um ensaio antropológico que aposta no distanciamento estratégico da já significativa produção etnográfica brasileira e internacional sobre práticas, valores, identidades e intervenções relativas à sexualidade, como movimento crucial para imaginar novas possibilidades de pesquisa e para construir novas pontes de interlocução entre pesquisadores. Bem visível na variedade de temas e objetos envolvidos nas pesquisas trazidas aos foros de discussão acadêmica nos últimos anos ${ }^{8}$ a dispersão dos estudos etnográficos sobre sexualidade pode ser considerada, de um lado, efeito da própria abordagem antropológica e de sua ênfase na produção de conhecimentos situados; de outro, parece derivar também da multiplicação de "sujeitos de pesquisa", ela mesma correlativa à crescente especificação identitária de sujeitos políticos e de direitos, ou seja, ao modo como a linguagem dos direitos, em particular dos direitos humanos, vem sendo acionada para reconfigurar a já antiga movimentação de diferentes "minorias sexuais" contra o estigma e a discriminação. Explorar os significados que os direitos sexuais adquirem no curso de sua elaboração e difusão, bem como no âmbito das políticas sexuais que eles simultaneamente pressupõem e justificam, permite refletir sobre a natureza das transformações por que passa o dispositivo da sexualidade (aggiornamento ou transformação radical?) e sobre a posição que, nesse processo, assume o discurso das ciências sociais, particularmente o da antropologia. 


\section{O dispositivo da sexualidade revisitado}

No plano dos saberes eruditos, o imperativo de falar sobre sexo, ponto de partida da reflexão foucaultiana sobre o dispositivo da sexualidade, parece à primeira vista estar não apenas em plena vigência, mas ter se intensificado enormemente nas últimas décadas. Sob o complexo e muitas vezes contraditório impacto do discurso dos movimentos pela "liberação sexual" das décadas de 1960/70; da emergência, na década seguinte, da epidemia da AIDS e do discurso em torno da "saúde sexual"; e, finalmente, da difusão da noção de direitos sexuais, ${ }^{9}$ característica da primeira década do século XXI, nunca se falou tanto sobre "sexo"; ao menos, não nas ciências sociais e, particularmente, na antropologia. ${ }^{10}$ Mas fala-se daquele mesmo "sexo" que, para Michel Foucault, teria sido o efeito histórico do próprio dispositivo da sexualidade?

Para esboçar respostas preliminares a estas questões, parto da hipótese de que a emergência da noção de direitos sexuais e a crescente utilização da linguagem dos direitos humanos para consolidar uma ampla agenda de reivindicações e intervenções no plano dos prazeres, dos corpos e das práticas sexuais significam mais que o mero reconhecimento de que essa dimensão da experiência humana foi alvo da ingerência autoritária do Estado no passado e de que precisa agora de proteção especial. Do ponto de vista aqui desenvolvido, a emergência da noção de direitos sexuais deve ser considerada aspecto central de um processo mais amplo de transformação que acontece no nível das políticas sexuais e incide sobre o próprio dispositivo da sexualidade. Como procuro explicitar abaixo, fruto da relação dinâmica entre diferentes atores sociais (ativistas, gestores públicos, políticos, juristas, pesquisadores etc.), tais direitos podem ser considerados como um símbolo da emergência histórica de um "novo" regime secular da sexualidade, acompanhado por um estilo de regulação moral que lhe é próprio.

Em suas linhas de força, o regime da sexualidade que se anuncia a partir do ideário dos direitos sexuais pode ser heuristicamente desenhado de modo contrastivo ao que foi descrito por Foucault, para quem, em oposição ao conjunto de princípios religiosos que capturavam o sexo e seus prazeres em uma linguagem centrada na carne, no pecado e no sacrifício, ${ }^{11}$ teria se forjado, ao longo do século XIX, e se difundido, na primeira metade do século $\mathrm{XX}$, um regime da sexualidade dotado de uma racionalidade, uma moralidade e uma política bastante particulares. ${ }^{12}$

De modo esquemático, podemos dizer que, no plano da racionalidade do "antigo" regime, o desejo sexual, sob a forma de um "instinto natural", 
figurava, como a fome, a sede ou o sono, enquanto necessidade fisiológica primária, sobre a qual os indivíduos, especialmente os homens, tinham pouco ou nenhum controle, ao menos não sem a ajuda de diferentes especialistas e mediadores. ${ }^{13}$ Esta concepção fazia com que os discursos das ciências biológicas e da medicina fossem considerados, entre os saberes eruditos, como os mais legítimos para "explicar" a sexualidade. Vozes alternativas eram ou tributárias dessa concepção, como no caso da sexologia, ${ }^{14}$ ou, como aconteceu com a psicanálise, francamente minoritárias até a segunda metade do século XX..$^{15}$ Assim, nesse plano, a sexualidade passou a ser apreendida, sobretudo, a partir de uma linguagem biomédica.

Quanto à moralidade, as relações sexuais e o prazer que se podia eventualmente delas usufruir legitimavam-se por sua dimensão reprodutiva ou por sua suposta capacidade de consolidar os vínculos amorosos que mantinham unido o casal (potencialmente) reprodutivo. Mesmo quando o prazer sexual era considerado também importante para manter o equilíbrio e a tonicidade do sistema nervoso de homens e mulheres, como apontavam alguns médicos na primeira metade do século XX (Carrara 1996), esses efeitos benéficos só seriam sentidos durante o período em que os corpos mantivessem seu potencial reprodutivo, ou seja, durante a chamada "idade fértil" (Carrara 2004). Isto equivale dizer, como têm feito inúmeros autores, que as fronteiras entre o bom e mau sexo eram, grosso modo, estabelecidas pelo caráter reprodutivo ou não das práticas sexuais. ${ }^{16}$

Por fim, no plano estritamente político, as intervenções estatais apoiavam-se no pressuposto de que à sexualidade vinculava-se o destino de um conjunto de entes transcendentais, como a "família", a "raça", a "nação" ou a "espécie". A sexualidade era, portanto, um interesse de Estado a que deviam estar submetidos os interesses particulares. Nesse âmbito, apenas tais entes transcendentais teriam "direitos"; os indivíduos tinham, sobretudo, obrigações e deveres. Nos códigos penais desse período, por exemplo, o que se protege é fundamentalmente o "direito" dos cidadãos de realizarem o ideal do casal monogâmico, dotado de prole mais ou menos numerosa. Condenavam-se, assim, conjuntamente, o adultério, o aborto, a prostituição, a homossexualidade, o defloramento, a sedução, o estupro, o rapto, a transmissão de doenças sexualmente transmissíveis etc. Enfim, um dos mais notáveis e conhecidos efeitos desse regime foi a entronização do casal heterossexual reprodutivo como norma biológica e moral, cuja promoção e defesa tornaram-se de "interesse público".

Considerado do ponto de vista atual, esse regime secular da sexualidade teria levado, no passado, a uma série de violações dos direitos humanos. Sobre alguns grupos, cujas práticas sexuais não visavam ou não 
permitiam uma reprodução considerada "saudável", desencadearam-se processos específicos de desumanização que implicaram sua morte social e, em alguns contextos nacionais, sua eliminação física. Foi o caso de prostitutas, homossexuais, portadores de doenças sexualmente transmissíveis e todo um rol de antigos libertinos que, "compreendidos" nas múltiplas categorias dos distúrbios psiquiátricos, passaram a ser considerados socialmente perigosos. ${ }^{17}$

É importante ressaltar que se em vários pontos esse regime secular da sexualidade se apoiava circunstancialmente na moral sexual cristã, ele também se opunha a ela, não podendo ser linearmente tomado como sua mera tradução em linguagem científica. Se, por exemplo, a partir de ambas as perspectivas, o casamento heterossexual era enfatizado como única forma aceitável de exercício pleno da sexualidade, isto se dava por razões inteiramente diferentes. Do ponto de vista da moral sexual cristã, enquanto rito e sacramento, o casamento vinculava-se a uma teologia que supunha uma arquitetura singular, na qual se valorizava a castidade, e o prazer sobretudo, o prazer sexual — só podia ser legitimado nos quadros mais amplos de uma ética do sacrifício. ${ }^{18} \mathrm{O}$ sexo heterossexual podia ser considerado sacrificial justamente por ser reprodutivo, representando a imolação dos prazeres conjugais diante da responsabilidade pela criação de filhos. ${ }^{19}$ Nesta perspectiva, sexo sem potencial reprodutivo deve ser considerado um ato egoísta, hedonista, despido de qualquer valor moral; um ato, enfim, "desordenado", expressão ainda hoje utilizada pelo Vaticano para se referir, por exemplo, às relações entre pessoas do mesmo sexo.

Do ponto de vista do regime secular da sexualidade implantado a partir do século XIX, nada disso fazia sentido. Se, em seus termos, o casal monogâmico heterossexual devia ser promovido, não era por ser sacrificial, mas por ser a configuração mais "natural" para a produção de uma prole sadia e eugênica, ou seja, por servir aos interesses do Estado em relação à manutenção e à reprodução de determinada "população" ou "raça". Sobre tais fundamentos, a técnica de gestão da população através da valorização do sexo reprodutivo abriu espaço para a proposição de medidas que, em muitos aspectos, eram condenáveis do ponto de vista da moral cristã. Como já é bem conhecido, a emergência da eugenia, ao menos em suas versões mais negativas, levava, por exemplo, à defesa do divórcio, da esterilização compulsória de "anormais" ou da obrigatoriedade de exames médicos pré-nupciais como maneira de garantir a "compatibilidade biológica" entre os cônjuges. ${ }^{20}$ Implicou, desse modo, a defesa de medidas incompatíveis com as doutrinas cristãs sobre o casamento e a sexualidade. 


\section{Um novo regime para a sexualidade?}

É na contraluz dessa configuração mais geral, desenhada em larga medida a partir das reflexões foucaultianas sobre o dispositivo da sexualidade, que se podem perceber as linhas mestras de um "novo" regime que, em finais do século XX, começa a se organizar em torno da noção de direitos sexuais, compreendidos como parte dos direitos humanos. Tais linhas emergem mais claramente no pós-Segunda Guerra, quando, sob a ação de diferentes processos sociais, a racionalidade, a moralidade e as concepções políticas que sustentavam o regime anterior começam a ser questionadas.

Não se trata aqui de retomar a trajetória dos "direitos sexuais". ${ }^{21}$ Mas é importante ressaltar que eles se vinculam à articulação de diferentes noções formuladas nas três últimas décadas do século XX, como as de "direitos humanos das mulheres", "direitos reprodutivos" ou direito à "saúde reprodutiva", definida como "capacidade de desfrutar de uma vida sexual satisfatória e sem riscos". Grosso modo, podemos dizer que, considerando o plano formal das declarações, das convenções e dos tratados relativos aos direitos humanos, essa trajetória parte do reconhecimento da necessidade de proteger juridicamente mulheres e meninas, vistas como sexualmente mais vulneráveis, para chegar à afirmação do direito a não discriminação baseada em orientação sexual e identidade de gênero. Ou seja, parte-se da ideia de proteção contra a violência sexual e da pouca autonomia das mulheres nas decisões reprodutivas para a afirmação da dignidade de diferentes formas de viver a sexualidade para além de seus aspectos reprodutivos.

Pressionada pela resposta política e cultural dos "outros" criados pela moral sexual anterior - articulada, sobretudo, a partir dos movimentos feministas e LGBT em luta pelo reconhecimento dos direitos sexuais — e também pela ação de desenvolvimentos paralelos, como a valorização do prazer sexual independente da reprodução (e até mesmo de laços afetivos) pelos saberes psi e sexológicos no pós-Segunda Guerra, ${ }^{22}$ a crescente preocupação com a explosão demográfica, a consolidação de um mercado erótico diversificado etc., o critério fundamental que separava o bom e o mau sexo se desloca progressivamente da reprodução biológica e da produção eugênica de uma população ou raça sadia para a promoção do bem-estar individual e coletivo através do bom uso dos prazeres. Em larga medida, o "sistema hierárquico de valor sexual" descrito por Rubin (1984), em cujo topo figurava solitário o casal heterossexual reprodutivo, sofreu importantes alterações nas últimas três décadas. O critério de avaliação moral das práticas sexuais passa a se basear, de um lado, na sua congruência com uma suposta verdade interior dos sujeitos expressa em seus desejos e, de outro, no pleno consentimento 
em participar das relações sexuais. Em suma, o exercício da sexualidade desloca-se em relação à lógica das obrigações conjugais ou cívicas, para ancorar-se na busca da realização pessoal, da felicidade, da saúde ou do bem-estar.

É interessante notar que o sistema de estratificação sexual concebido por Rubin nos anos 1980 parece desenhar uma moralidade a meio caminho entre os dois regimes da sexualidade aqui propostos. Diferentemente do que ela observava então, no topo de tal sistema, casais heterossexuais reprodutivos não estão mais "sozinhos"; nem gays e lésbicas, cujas relações conjugais vêm sendo juridicamente reconhecidas em um número cada vez maior de países ocidentais, continuam situados em algum lugar no meio da pirâmide, junto com os adeptos do uso de sex toys ou de práticas sadomasoquistas. ${ }^{23}$ Apesar disso, a camada mais inferior da hierarquia sexual possivelmente continua a ser ocupada por aqueles "cujo erotismo transgride fronteiras geracionais" (Rubin 1989:279, tradução própria). O "sistema" que Rubin descreve em meados dos anos 1980 parece ser assim uma "fotografia", uma visão congelada de um processo dinâmico de "mobilidade sexual", para a qual a própria difusão da reflexão da autora deve ter seguramente contribuído. Nesse sentido, Rubin propõe uma moral sexual ideal que subjaz aos desenvolvimentos posteriores que serão aqui apontados, muitas vezes assumindo um caráter prescritivo. Em suas palavras:

Uma moralidade democrática deveria julgar os atos sexuais pelo modo como os parceiros se tratam, o nível de respeito mútuo, a presença ou ausência de coerção e a quantidade e qualidade dos prazeres que eles proporcionam. Não deveria ser foco de preocupação ética se os atos sexuais são gays ou heterossexuais, realizados em casal ou em grupo, nus ou com roupa íntima, comercial ou gratuito, com ou sem vídeo (1989:283, tradução própria).

Correlativo a esse deslocamento no plano da moralidade, o sexo vai progressivamente deixando de ser visto como uma força fisiológica incoercível - o instinto (heterossexual) reprodutivo - para se tornar uma tecnologia de si, uma técnica que os indivíduos podem e devem saber manejar para serem mais felizes e realizados, ou seja, a essa mudança na moralidade correspondeu uma mudança paralela no plano da racionalidade. Na vaga das críticas que, depois dos anos 1960, recaíram sobre o caráter autoritário de um discurso científico que, em grande medida, extraía seu poder da "crença" em um determinismo generalizado, a linguagem biomédica que se organizava em torno da noção de instinto e do axioma do sexual essentialism (1989:275) vai ceder lugar à outra, articulada agora em torno da noção de 
que a sexualidade é matéria muito mais plástica do que se supunha. Como no caso da raça ou do gênero, ela seria, segundo diferentes abordagens críticas, socialmente moldada, condicionada ou construída até mesmo em seus aspectos ou efeitos mais "materiais" (Vance 1995). Toda sorte de injunções culturais, sociais, políticas e econômicas a constituiriam como plano discreto da experiência humana e como objeto "natural" da reflexão científica.

Finalmente, se a política do "antigo" regime estabelecia uma relação de intensa subordinação dos prazeres individuais aos interesses de Estado, torna-se cada vez mais difícil justificar qualquer regulação sexual pela defesa de entes transcendentais, como a raça ou a nação. As estratégias de intervenção alteram-se e qualquer regulação só pode agora ser plenamente justificada em nome da preservação ou da promoção da cidadania ou da saúde (física ou mental) dos próprios indivíduos envolvidos ou implicados. É a sexualidade "irresponsável" que deve ser coibida ou combatida.

Mesmo que a afirmação do critério moral da liberdade/consentimento, a crítica à teoria do instinto e a preeminência dos interesses individuais possam ser abordadas como desenvolvimentos paralelos, com suas dinâmicas e ritmos particulares, elas se entrelaçam e se apoiam mutuamente. Sua articulação faz com que seja possível conceber a passagem de um regime secular da sexualidade, cuja linguagem era predominantemente biomédica, para um regime que se formula cada vez mais completamente em uma linguagem socio-jurídica, para a qual, é importante destacar, os antropólogos têm aportado importante contribuição (Duarte 2004). É interessante perceber como tal linguagem passa a organizar o próprio discurso médico-psiquiátrico. Os critérios da consensualidade e da responsabilidade, por exemplo, tornam-se cruciais para a definição mesma das parafilias, ou seja, das antigas perversões sexuais, entre as quais figurava a homossexualidade. Nas últimas décadas do século XX, em diferentes edições do influente Manual diagnóstico e estatístico de transtornos mentais (DSM), da Associação Psiquiátrica Americana, as parafilias não são mais medidas pela distância que mantinham em relação ao coito reprodutivo/heterossexual, mas a cobrir desejos e práticas sexuais não consentidas e, conforme a última versão do próprio Manual, "cuja satisfação provocou dano pessoal, ou risco de dano, a outros" (DSM-5:685, tradução própria). Estranho fenômeno o das novas definições das antigas perversões, que passam a ser tanto mais "doenças" quanto mais se aproximam de comportamentos criminosos. ${ }^{24}$

Seja por manter vivo o ideário da liberação sexual, seja por promover a "cidadania sexual" ou a "democracia sexual" (Béjin 1985), esse "novo" regime é considerado por muitos ativistas e intelectuais como um "avanço" em relação ao regime "anterior". Embora, de várias perspectivas, esse "avanço" pareça 
inegável, é também bastante evidente que, em seus termos, desenha-se uma nova geografia do mal e do perigo sexual. Nesse sentido, os processos de medicalização e criminalização, que antes atingiam principalmente indivíduos ou grupos não reprodutivos ou os que exerciam sua sexualidade fora das "paredes" da conjugalidade heterossexual, voltam-se progressivamente para outros focos: (i) para os que, por não reconhecerem seus próprios desejos, ou por alguma outra razão orgânica ou psíquica, não conseguem extrair do sexo um prazer considerado satisfatório ${ }^{25}$ (ii) para os que não teriam autocontrole suficiente em face do próprio desejo sexual, colocando a integridade de si e de outros em risco; ${ }^{26}$ (iii) os que, segundo os novos critérios, sentiriam desejos indesejáveis, ou seja, aqueles cujo interesse sexual se volta para sujeitos cujo pleno consentimento não se pode assegurar. ${ }^{27}$ De modo geral, nesse novo regime, desde que sejam consentidas e que não coloquem a si próprio ou a terceiros em risco, quaisquer manifestações da sexualidade (e também das expressões de gênero) podem idealmente pleitear o direito de cidadania, articulando suas demandas na linguagem dos direitos humanos.

A esse regime secular da sexualidade corresponderia, portanto, uma nova sensibilidade social, cujo foco gira em torno de outros pontos. De um lado, em torno do sexo entre pessoas desigualmente investidas de poder (sobre o qual passa a pairar a sombra da violência presumida). De outro, em torno daqueles e daquelas que parecem exercer pouco ou nenhum controle sobre seus próprios impulsos e paixões. Desse modo, aumenta a inquietação (que às vezes assume a dimensão de pânico moral) em relação a fenômenos como a pedofilia, o assédio sexual, o abuso sexual, o turismo sexual, a exploração sexual, a compulsão sexual etc.

Talvez seja mais apropriado afirmar que, no âmbito desse regime e dentro dos limites que ele impõe, diferentes práticas e desejos mudarão de sentido. Algumas drasticamente, como é o caso da homossexualidade, que passa a ser tão legítima e merecedora de respeito quanto a heterossexualidade. Ou ainda mais do que ela, uma vez que, como prática sexual "entre iguais", pode se constituir em modelo para as próprias relações heterossexuais, presas a uma (ainda) inescapável hierarquia de gênero. Michael Pollak já apontava, em um sentido um pouco diferente do adotado aqui, para o caráter modelar que a homossexualidade ou a "vida homossexual" assumia nas sociedades europeias e nos Estados Unidos no pós-Segunda Guerra. Em artigo publicado originalmente em 1982, depois de observar que, para os sexólogos Masters e Johnson, homossexuais teriam menos problemas sexuais que heterossexuais, o sociólogo se perguntava: "Será que os homossexuais logo viverão em uma sociedade que não só os tolera, mas reconhece neles qualidades a serem imitadas?" (Pollak 1985:73). 
Pollak argumentava que a homossexualidade se tornava modelar porque simbolizava o ápice do "duplo movimento tendencial de autonomização relativa e de racionalização da sexualidade", impulsionada em um momento em que a "liberação geral dos costumes sexuais" separava a sexualidade da procriação e das relações afetivas (:57). Ironicamente, a emergência da Aids em meados dos anos 1980 e o desenvolvimento de novas técnicas de reprodução assistida iriam transformar profundamente o "modo de vida homossexual", contribuindo para reinscrevê-lo no sistema de trocas conjugais e da parentalidade. Se podemos ainda considerar a homossexualidade modelar, não é mais porque apresenta o máximo de "rendimento" sexual, mas sim porque idealmente institui um espaço em que as relações seriam mais igualitárias ou simétricas.

Outras práticas que, no regime "anterior", já eram condenadas ou criminalizadas, continuarão a sê-lo, mas segundo outros princípios. É, por exemplo, o caso do estupro que, de um crime contra os costumes, passou a ser considerado como um crime contra a pessoa, tendo suas penas aumentadas. Ou ainda o caso do aborto que, se era condenável por manifestar uma recusa à procriação, o é agora por ser o sinal de uma sexualidade fora de controle ou, ao menos, imprevidente. Além disso, entre o aborto e o abuso sexual de crianças e adolescentes parece se estabelecer uma subterrânea relação simbólica, uma vez que, em ambos os casos, o preço de um prazer imprevidente seria pago por uma "vítima inocente". Finalmente, outras práticas ou desejos que antes não mereciam qualquer atenção da medicina ou do direito começam a ser codificados ou como crimes, como no caso do assédio sexual, ou como patologia, como no caso da compulsão sexual.

\section{As políticas sexuais como campo de compromissos}

Obviamente a oposição entre esses dois regimes, aqui apresentados como tipos ideais, é sobretudo heurística. Uma das complexidades desse processo é que, embora datáveis, eles não são sucessivos no tempo, mas convivem tensamente no cenário contemporâneo. Em distintos modos de articulação, de colisão ou de enfrentamento, desenham diferentes políticas sexuais e estilos de regulação moral. Além disso, interagem e se articulam com as prevalentes moralidades cristãs. Assim, se é possível falar de um processo histórico de transformação ou de passagem de um regime a outro, ele é sem dúvida tecido lentamente, através de continuidades, rupturas e, às vezes, de inesperados compromissos.

Tome-se como exemplo a possibilidade do pleno reconhecimento legal das relações entre pessoas do mesmo sexo. De modo geral, no universo das 
religiões cristãs, casar duas pessoas do mesmo sexo continua a ser visto como uma subversão da própria instituição do casamento. Porém, em face das crescentes pressões em relação à democratização da lei do casamento civil, passo crucial do processo mais amplo de cidadanização da diversidade sexual e de gênero, a teologia cristã vai se transformando. Pode muito bem, como já acontece em algumas igrejas chamadas de "inclusivas", ${ }^{28}$ reinterpretar o significado de "reprodução", justificativa fundamental do casamento, deslocando seu sentido do eixo biológico para o eixo social. $\mathrm{O}$ problema passaria a ser então o sexo socialmente "estéril", ou seja, aquele que não produz laços ou vínculos afetivos estáveis, perdendo-se no êxtase da "promiscuidade". Aliás, é importante ressaltar como a "promiscuidade sexual" apresenta-se hoje como forte candidata a ser uma espécie de "categoria-ponte" entre formulações da moral sexual cristã e o "novo" regime secular da sexualidade, em cujos termos ela pode aparecer como uma das figuras do descontrole sobre si, sendo acionada em contextos em que a AIDS e outras doenças sexualmente transmissíveis ou a gravidez na adolescência estão em questão.

Valores oriundos dessas diferentes moralidades podem também ser simultaneamente acionados quando se trata de lutar por certos direitos ou combatê-los. Um movimento importante no esforço para barrar o reconhecimento de qualquer direito civil aos "outros" da "antiga" moral sexual e que hoje são agregados sob a sigla LGBT é, por exemplo, equacionar homossexualidade e pedofilia. Usa-se aqui um comportamento absolutamente condenável do ponto de vista do "novo" regime da sexualidade, a pedofilia, para manter vivo o velho critério da reprodução e da heterossexualidade como valores fundamentais na estratificação sexual. Por seu lado, os que defendem a extensão dos direitos civis à população LGBT podem estrategicamente enfatizar a "normalidade" das relações entre pessoas do mesmo sexo, ressaltando que também envolvem afetividade, criam laços e famílias; ou ainda apoiar-se no discurso médico para promover o direito à livre determinação do sexo ou gênero a que se quer pertencer, como no caso da transexualidade. ${ }^{29}$

Além disso, se no novo cenário de valorização da sexualidade para além da reprodução, os discursos biomédicos voltam-se para outros focos, eles não deixam de permanecer, em alguns pontos, em clara tensão com a emergente linguagem sociojurídica. As pesquisas que buscam as bases genéticas da homossexualidade, ${ }^{30}$ por exemplo, continuam a naturalizar o desejo sexual entre pessoas do mesmo sexo mesmo que não seja mais para delinear os contornos de uma patologia ou o caráter imperioso de um instinto, mas para "apenas" demonstrar que a homossexualidade representa 
uma variação natural da sexualidade humana. Oferecem, assim, uma plataforma que, em contradição com a racionalidade característica do "novo" regime da sexualidade, não deixa entretanto de ser utilizada, mesmo que estrategicamente, ${ }^{31}$ na defesa dos direitos de cidadania de certos grupos.

O que vemos, portanto, é que a política sexual, em seu caráter heterogêneo e instável, vai articulando, em cada momento histórico e contexto nacional, concepções, valores e técnicas de intervenção de ambos os regimes. O que obviamente não significa dizer que, nessa espécie de colcha de retalhos que são as políticas sexuais contemporâneas, algumas cores e formas não predominem ou que algumas linhas de força não ganhem destaque e desenhem um horizonte possível de transformações. E, do que se pode perceber a partir do contexto atual, a sexualidade, ao que parece, estará cada vez mais sendo regida pelo signo dos direitos sexuais.

\section{Considerações finais}

Tendo em vista as tensões, as contradições e as mediações entre os princípios que regem idealmente os dois regimes acima esboçados, pode-se dizer que o projeto disciplinar da anátomo-política dos corpos, que caracterizava o dispositivo da sexualidade, continua presente. De modo geral, como vimos, no que diz respeito à sexualidade, as expectativas relativas à subjetivação, à responsabilização e ao controle de si aprofundam-se enormemente. Quase nada mais parece ser desculpável ou inocente nessa matéria. Porém, não parecem mais tão claros ou imediatos os efeitos biopolíticos do dispositivo sobre as populações, uma vez contestado o ideal do casal reprodutivo e vinculando-se a sexualidade, agora a partir de novos laços, ao direito e à lei e não mais às biociências e suas normas. O sexo estaria deixando de ser, como pensava Foucault, o "acesso ao mesmo tempo à vida do corpo e à vida da espécie" (1976:137), perdendo assim seu caráter estratégico do ponto de vista do biopoder? Estaríamos vendo, ao menos nesse aspecto, o desmantelamento parcial do dispositivo através do resultado "vitorioso" das lutas por aquela espécie de "'direito' à vida, ao corpo, à saúde, à felicidade, à satisfação das necessidades, o 'direito' de encontrar tudo o que se é e tudo o que se pode ser" que, como pensava Foucault, teria o poder de minar o bom funcionamento do dispositivo a partir de seu próprio interior (1976:136)?

Mas talvez não estejamos falando mais nem do mesmo "sexo", nem do mesmo "direito", e os efeitos biopolíticos se façam sentir agora de modos mais sutis e indiretos. As atuais preocupações em relação ao sexo não consentido ou em relação ao preconceito e à discriminação homofóbica, por 
exemplo, têm desenhado vastas categorias de "vulneráveis". E em nome de sua proteção, instalam-se controles sobre fluxos populacionais, como é o caso das renovadas preocupações com a permeabilidade das fronteiras entre os Estados nacionais, em jogo na luta contra o tráfico de pessoas para prostituição. Do mesmo modo, mesmo que a heterossexualidade reprodutiva possa ser destituída de sua posição normativa, as "crianças" continuam no centro das preocupações. Posicionadas como a mais vulnerável das categorias sociais nos termos do novo regime da sexualidade, sua proteção contra a exploração e o abuso vem justificando recentemente toda uma série de controles sobre fluxos populacionais reais ou virtuais. Além disso, outras hierarquias vêm sendo produzidas, separando países ou regiões em que os direitos sexuais são respeitados daqueles em que eles não o são, desenhando uma nova geopolítica sexual.

Enfim, as políticas sexuais são dinâmicas e o destino do dispositivo da sexualidade permanece indefinido. Como dito acima, a postulação desses dois regimes seculares da sexualidade e, sobretudo, do processo de passagem do primeiro para o segundo é uma construção formal. Seu valor deve ser estabelecido apenas na medida em que seja capaz, a partir da elaboração de um quadro interpretativo mais abrangente, de contribuir para motivar novas pesquisas etnográficas ou outras leituras dos resultados de diferentes investimentos etnográficos já realizados e, principalmente, na medida em que seja capaz de propiciar que os estudos sobre diversidade sexual e de gênero dialoguem mais sistematicamente com os estudos desenvolvidos sobre outros temas, no âmbito de uma reflexão mais ampla sobre a sexualidade.

Recebido em 26 de março de 2015

Aprovado em 29 de maio de 2015

Sérgio Carrara é antropólogo, Professor Associado do Instituto de Medicina Social (IMS/UERJ) e pesquisador do Centro Latino-Americano em Sexualidade e Direitos Humanos (CLAM). E-mail:< scarrara1@gmail.com> 


\section{Notas}

${ }^{1}$ Tais expressões estavam presentes no Plano Nacional de Educação (PNE), enviado pelo Executivo para aprovação no Congresso em finais de 2010 através do Projeto de Lei 8035/2010. O Plano foi elaborado a partir dos resultados da Conferência Nacional de Educação (CONAE), realizada no início daquele ano. Segundo o Documento Final da CONAE (Brasil 2010), em todas as suas etapas, a conferência teria mobilizado 3,5 milhões de pessoas. Com inúmeras alterações, o projeto se transformaria em lei em junho de 2014 (Lei 13005/2014). Nesse processo, substituíram-se trechos como o que dizia "são diretrizes do PNE a superação das desigualdades educacionais, com ênfase na promoção da igualdade racial, regional, de gênero e de orientação sexual" por: "são diretrizes do PNE a superação das desigualdades educacionais, com a ênfase na erradicação de todas as formas de discriminação".

${ }^{2}$ Ver (http://arqrio.org/noticias/detalhes/1835/nota-sobre-o-pne). Acesso em $18 / 06 / 2015$.

${ }^{3}$ Privilegio neste texto "diversidade sexual e de gênero" como forma de evitar expressões mais comprometidas com antigas categorias médicas, como "homossexualidade", ou com as atuais categorias identitárias, como "lésbicas", "gays", "bissexuais", "travestis" e "transexuais", que se firmam no plano político nacional e internacional através da sigla "LGBT". Para uma apreciação mais geral da história do movimento LGBT no Brasil, ver, entre outros, Facchini (2005); Simões \& Facchini (2009); Carvalho (2011).

${ }^{4}$ A expressão cidadanização foi originalmente trabalhada por Duarte et al. (1993) em artigo que abordava as ações que, nos anos 1980, organizações não governamentais desenvolviam em bairros populares do Rio de Janeiro. Tratando-se de um amplo projeto de incorporação social e política de categorias sociais marginalizadas que se apoia sobre o triplo processo de individualização, racionalização e responsabilização, o conceito parece-me apropriado também para a análise do que vem acontecendo desde os anos 1960 em diferentes países ocidentais com a diversidade sexual e de gênero.

${ }^{5}$ A ideia de que gerir, regular, administrar ou controlar são os modos privilegiados de ação do poder estatal deriva claramente das reflexões de Michel Foucault $(1975,1976)$ e se contrapõe a visões mais tradicionais que concebem tal ação como essencialmente limitante e não produtiva, não propositiva, não criadora.

${ }^{6}$ Os estudos sobre a importância da sexualidade (ou do estilo de regulação moral suposto em seu dispositivo) para os processos sociais e políticos de constituição dos sujeitos modernos, com seus imperativos de reflexividade, de controle de si, de engajamento político e social (consciência de seus direitos e deveres), têm sido a preocupação de diferentes autores, entre os quais, destaca-se Duarte (2004). 
${ }^{7}$ Nessa direção, parece pertinente a observação de Weeks quando, referindo-se especificamente à reflexão contida no primeiro livro da história da sexualidade de Foucault, diz que "ao enfatizar o papel da norma [Foucault] está conscientemente diminuindo o papel do Estado - ao menos como expresso em seu aparato legal - e ao fazê-lo, subestima seu papel na construção de atitudes ligadas à sexualidade através das leis do casamento, da regulação do desvio, do judiciário, da polícia, bem como, de forma mais geral, do sistema educacional, do sistema previdenciário, e assim por diante. A regulação é exercida tanto através 'da norma' quanto do poder político. Foucault não negaria isto, é claro, mas ao enfatizar a 'norma' sobre a lei corre o risco de ignorar importantes transformações políticas" (Weeks 1989:8-9, tradução própria, grifo meu).

${ }^{8}$ Uma reflexão preliminar sobre tal dispersão foi ensaiada por mim em artigos recentes (Carrara 2013; Simões \& Carrara 2014).

${ }^{9}$ Embora apresente fronteiras semânticas imprecisas, incluindo para muitos autores o direito à livre expressão de gênero (Almeida 2012), a noção vem sendo definida em um campo no qual as ciências sociais dialogam ativamente com ativistas e juristas. Para isso, ver Petcheski (1999); Correa (2004); Rios (2006, 2007).

${ }^{10}$ Mesmo com escopo temático circunscrito, a revisão empreendida recentemente por Facchini et al. (2013) aponta claramente nesse sentido.

${ }^{11}$ Para uma discussão mais ampla sobre os fundamentos da moral sexual cristã, ver Foucault \& Sennet (1981); Ariès (1985 [1982]); Pagels (1989); Brown (1990); Duarte \& Giumbelli (1995).

${ }^{12}$ A separação entre os planos da racionalidade, ou dos saberes, da moralidade e da política é aqui apenas instrumental. Parte significativa da antropologia contemporânea dedica-se justamente a explorar etnograficamente as tensões e as articulações entre esses diferentes planos. Para um exemplo particularmente feliz desse tipo de abordagem, ver Vianna \& Farias (2011).

${ }^{13}$ Muitos autores já se voltaram para essa concepção fundamental, dentre os quais destaco Weeks (1985).

${ }^{14}$ Para uma visão mais complexa dos diferentes paradigmas que orientaram a sexologia ao longo do século XX, ver o clássico trabalho de Paul Robinson (1977).

${ }^{15}$ No plano dos saberes eruditos, as tensões entre as dominantes abordagens fisicalistas da sexualidade, de matiz racionalista, e as que, em contraponto, privilegiavam a subjetividade, de matiz romântico, têm sido extensamente apontadas por Luiz Fernando Dias Duarte (2004). Sobre a história da difusão da psicanálise no Brasil, ver Russo (2002, 2007); e sobre suas relações com a sexologia, Russo \& Carrara (2002).

${ }^{16}$ Esta ideia vem sendo reafirmada por uma extensa literatura sociológica, antropológica e histórica, em diálogo com a crítica feminista e o ativismo relativo 
à diversidade sexual e de gênero. Sobre este ponto, acompanho as observações de Gayle Rubin (1984) e Carole Vance (1989).

${ }^{17}$ Concebida como uma ameaça à família, à raça, à nação, a homossexualidade, por exemplo, passou a ser vista como doença ou anomalia, devendo ser erradica pelos médicos, com o apoio cúmplice das famílias (Green 2000). Pelas mesmas razões, em muitos contextos nacionais, a prostituição passou a ser rigidamente controlada por um dispositivo médico-policial - o "regulamentarismo" - e, em outros, foi criminalizada e duramente perseguida. Abordando diferentes contextos nacionais, há uma vasta literatura sobre o tema, da qual destaco: Corbin (1982); Rago (1991); Walkowitz (1983); Guy (1990); Engel (1989); Brandt (1985).

${ }^{18}$ Para muitos um sinal de eleição divina, o ideal era a abstinência sexual ou castidade, inicialmente esperada de todos os fiéis e, posteriormente, exigida apenas para os sacerdotes (Ariés 1985 [1982]).

${ }^{19}$ Segundo Flandrin, até o século XVII, "a maioria dos teólogos julgava que [até] os esposos que se uniam ao cônjuge por prazer também cometiam um pecado mortal" (Flandrin 1985:136).

${ }^{20}$ Sobre as políticas eugênicas no Brasil, ver Stepan (1990, 1996).

${ }^{21}$ Para isso ver, entre outros, Rios (2006).

${ }^{22}$ Para isso, ver, entre outros, Béjin (1985) e Robinson (1977).

${ }^{23}$ Para uma análise sobre a crescente legitimação social do uso de sex toys, da frequência a sex shops, da adesão a práticas sadomasoquistas, ou do consumo da pornografia, ver Gregori (2011, 2012); Zilli (2009). Ao analisar certos aspectos do mercado sexual atual, Gregori aponta para o mesmo deslocamento que observo no plano das moralidades. Para ela, essa nova face do mercado erótico implica "o deslocamento do sentido de clandestinidade do erotismo para um significado cada vez mais associado ao cuidado saudável do corpo e para o fortalecimento do self" (Gregori 2010:43).

${ }^{24}$ Sobre este ponto, ver Giami (2015).

${ }^{25}$ Russo empreende uma importante análise sobre o modo pelo qual, enquanto algumas antigas doenças ou distúrbios da sexualidade desaparecem das sucessivas versões do DSM, outras as substituem. Apontando para a complexidade e a heterogeneidade do processo de desmedicalização da sexualidade, a antropóloga ressalta que, ao mesmo tempo em que as antigas figuras do excesso sexual e das parafilias tendem a desaparecer, como aconteceu com a homossexualidade em 1973, as novas patologias inclinam-se geralmente para se estruturar em torno de faltas, ausências ou carências - sejam elas da libido, da ereção/excitação ou do prazer. Ao que parece, para a psiquiatria contemporânea, como ressalta a autora, sexo "nunca é demais" (Russo 2004, 2009). Talvez isto explique o fato de que, enquanto categorias diagnósticas, a inibição do desejo sexual tenha sido formulada por médicos e sexólogos, e o 
seu oposto, a adição sexual, tenha sido forjada inicialmente em grupos de autoajuda, conforme analisa Irvine (2013 [1991]).

${ }^{26}$ Para uma instigante análise antropológica dos grupos de autoajuda organizados em torno da adicção ou compulsão sexual no contexto brasileiro, ver Ferreira (2013).

${ }^{27}$ Para uma discussão sobre o tema no âmbito das discussões sobre pedofilia, ver Lowenkron (2015). As discussões contemporâneas sobre a prostituição também recolocam, no contexto do combate ao tráfico de pessoas e à exploração sexual, os dilemas em relação à liberdade e ao consentimento. Para isso, ver Piscitelli $(2011,2014)$.

${ }^{28}$ Para um panorama das formulações sobre sexualidade das chamadas igrejas "inclusivas", no horizonte do universo evangélico no país, ver Natividade (2006, 2010); Machado \& Piccolo (2010); Weiss de Jesus (2010).

${ }^{29}$ De fato, no contexto atual, o estatuto da transexualidade como "disforia de gênero" está no cerne de acirradas disputas que mobilizam profissionais, ativistas e pesquisadores. Para isso, ver, entre outros, Almeida \& Murta (2013); Bento \& Pelucio (2012); Teixeira (2013).

${ }^{30}$ Para apreciação crítica de tais teorias, ver Nucci \& Russo (2009); Nucci (2010).

${ }^{31}$ Para uma interessante discussão em torno da noção de "essencialismo estratégico", aplicado ao campo de disputas que envolve o caráter natural ou não das orientações sexuais, ver Vale de Almeida (2009).

\section{Referências bibliográficas}

ALMEIDA, Guilherme S. de. 2005. Da invisibilidade à vulnerabilidade: percurso do corpo lésbico na cena brasileira face à possibilidade de infecção por DST e Aids. Tese de Doutorado em Saúde Coletiva, Universidade do Estado do Rio de Janeiro. - 2012. "'Homens trans': novos matizes na aquarela das masculinidades?". Revista Estudos Feministas, 20(2): 513-523, maio-agosto/2012

ALMEIDA, Guilherme S. de \& MURTA, Daniela. 2013. "Reflexões sobre a possibilidade da despatologização da transexualidade e a necessidade da assistência integral à saúde de transexuais no Brasil". Sexualidad, Saludy Sociedad-Revista Latino-Americana, 14:380-407.

ARIÉS, Philipe. 1985 [1982]. "São Paulo e a carne". In: P. Ariés \& A. Béjin (orgs.), Sexualidades Ocidentais. São Paulo: Brasiliense. pp. 50-53.

BALTHAZAR, Adriana Maria S. e. 2012. O lugar do silêncio na violência homofóbica: o dizível e o indizível nas narrativas de sofrimento. Dissertação de Mestrado em Saúde Coletiva, UERJ. 
BENTO, Berenice \& PELUCIO, Larissa. 2012. "Despatologização do gênero: a politização das identidades abjetas". Revista Estudos Feministas, 20(2):569-581.

BÉJIN, André. 1985. "Crepúsculo dos psicanalistas, manhã dos sexólogos". In: P. Ariés \& A. Béjin (orgs.), Sexualidades Ocidentais. São Paulo: Brasiliense. pp. 210-235.

BRANDT, Allan M. 1985. No magic bullet: a social history of venereal disease in the United States 1880. New York/ Oxford: Oxford University Press.

BRASIL. 2010. Construindo o sistema nacional articulado de educação: O plano nacional de educação, diretrizes e estratégias de ação (Documento Final). Brasília: Ministério da Educação.

BROWN, Peter. 1990. Corpo e sociedade; o homem, a mulher e a renúncia sexual no início do Cristianismo. Rio de Janeiro: Jorge Zahar.

CARRARA, Sérgio. 1996. Tributo a Vênus: a luta contra a sífilis no Brasil, da passagem do século aos anos 40. Rio de Janeiro: Fiocruz.

. 2004. "Une science dérisoire: l'andrologie au Brésil entre les deux guerres". Vibrant, 1(1):256-274.

_.2013. "Négocier les frontières, négocier aux frontières: l'anthropologie et le processus de 'citoyennisation' de l'homosexualité au Brésil". Brésil(s). Sciences Humaines et Sociales, 4:103-123.

CARVALHO, Mario F. de L. 2011. Que mulher é essa? Identidade, política e saúde no movimento de travestis e transexuais. Dissertação de Mestrado em Saúde Coletiva, UERJ.

CORBIN, Alain. 1982. Les filles de noces. Paris: Flammarion.

CORREA, Sônia. 2004. "Direitos sexuais numa perspectiva internacional e histórica". In: Veriano Terto Jr. et al. (org.), Direitos sexuais e reprodutivos como direitos humanos. Porto Alegre: Nupacs/UFRGS. pp. 7-16.
DUARTE, Luiz F. D. 2004. "A sexualidade nas ciências sociais: leitura crítica das convenções". In: A. Piscitelli; M. F. Gregori \& S. Carrara, Sexualidade e saberes: convenções e fronteiras. Rio de Janeiro: Garamond. pp. 39-80.

DUARTE, Luiz F. D.; BARSTED, Leila; TAULOIS, Maria R. \& GARCIA, Maria H. 1993. "Vicissitudes e limites da conversão à cidadania nas classes populares brasileiras". Revista Brasileira de Ciências Sociais, 22(1):5-19.

DUARTE, Luiz F. D. \& GIUMBELLI, Emerson. 1995. "As concepções cristã e moderna de pessoa: paradoxos de uma continuidade". Anuário Antropológico, 93:7-111.

ENGEL, Magali, G. 1989. Meretrizes e doutores: saber médico e prostituição no Rio de Janeiro (1840-1890). São Paulo: Brasiliense.

FACCHINI, Regina; DANILIAUSKAS, Marcelo \& PILON, Ana C. 2013. "Políticas sexuais e produção de conhecimento sobre gênero e (homo)sexualidades no Brasil". Revista de Ciências Sociais, 44(1):161-193.

FACCHINI, Regina. 2005. Sopa de letrinhas? Movimento homossexual e produção de identidades coletivas nos anos 90. Rio de Janeiro: Garamond.

FERREIRA, Carolina B. de C. 2013. "A emergência da adicção sexual, suas apropriações e as relações com a produção de campos profissionais". Sexualidade, Saúde e Sociedade - Revista Latino-Americana, 14:284-318.

FLANDRIN, Jean-Louis. 1985. "A vida sexual dos casados na sociedade antiga: da doutrina da Igreja à realidade dos comportamentos". In: P. Ariés \& A. Béjin (orgs.), Sexualidades Ocidentais. São Paulo: Brasiliense. pp. 135-152.

FOUCAULT, Michel. 1975. Vigiar e punir: a história da violência nas prisões. Rio de Janeiro: Graal. 
- 1976. História da sexualidade I. A vontade de saber. Rio de Janeiro: Graal.

FOUCAULT, Michel \& SENNETT, Richard. 1981. "Sexuality and solitude: an interview with Richard Sennet". London Review of Books, 21:03-07.

GIAMI, Alain. 2015. "Between DSM and ICD: paraphilias and the transformation of sexual norms". Archives of Sexual Behavior, 44(5):1127-1138.

GREEN, James. 2000. Além do carnaval: a homossexualidade masculina no Brasil do século XX. São Paulo: Editora Unesp.

GREGORI, Maria F. 2010. Prazeres perigosos: erotismo, gênero e os limites da sexualidade. Tese de Livre Docência, IFCH/Unicamp.

- 2011. "Usos de sex toys: a circulação erótica entre objetos e pessoas". Mana. Estudos de Antropologia Social, 17(2): 313-336.

. 2012. "Erotismo, mercado e gênero. Uma etnografia dos sex shops de São Paulo, Campinas". Cadernos Pagu, 38:53-97.

GUY, Donna. J. 1990. Sex and danger in Buenos Aires: prostitution, family, and nation in Argentina. Lincoln/London: University of Nebrasca Press.

IRVINE, Janice M. 2013 [1991]. “Paixões reguladas: a invenção da inibição do desejo sexual e da adicção sexual". Sexualidade, Saúde e Sociedade - Revista Latino-Americana, 15:148-177.

LEITE, Vanessa J. 2013. Sexualidade adolescente como direito? A visão de formuladores de políticas públicas. Rio de Janeiro: Eduerj.

• 2014. "Impróprio para menores?". Adolescentes e diversidade sexual e de gênero nas políticas públicas brasileiras. Tese de Doutorado em Saúde Coletiva, UERJ.

LOWENKRON, Laura. 2015. O monstro contemporâneo: a construção social da pedofilia em múltiplos planos. Rio de Janeiro: Eduerj.
MACHADO, Maria D. C. \& PICCOLO, Fernanda D. (orgs.). Religiões e homossexualidades. Rio de Janeiro: FGV.

NATIVIDADE, Marcelo T. 2006. "Homossexualidade, gênero e cura em perspectivas pastorais evangélicas". Revista Brasileira de Ciências Sociais, 21(61):115-132. . 2010. "Uma homossexualidade santificada? Etnografia de uma comunidade inclusiva pentecostal". Religião \& Sociedade, $30(2): 90-121$.

NUCCI, Marina F. 2010. Hormônios pré-natais e a ideia de sexo cerebral: análise das pesquisas biomédicas sobre gênero e sexualidade. Dissertação de Mestrado em Saúde Coletiva, UERJ.

NUCCI, Marina F. \& RUSSO, Jane A. 2009. "O terceiro sexo revisitado: a homossexualidade no Archives of Sexual Behavior". Physis - Revista de Saúde Coletiva, 19(1):127-147.

PAGELS, Elaine. 1989. Adam, Eve et le serpent. Paris: Flammarion.

PAZO, Concepcion G. 2013. Novos frascos, velhas fragrâncias: a institucionalização da Lei Maria da Penha em uma cidade fluminense. Tese de Doutorado em Saúde Coletiva, UERJ.

PETCHESKY, Rosalind P. 1999. "Direitos sexuais: um novo conceito na prática política internacional". In: R. M. Barbosa \& R. Parker (orgs.), Sexualidades pelo avesso: direitos, identidades e poder. Rio de Janeiro: Editora 34. pp. 15-38.

PISCITELLI, Adriana G. 2011. “Entre os discursos sobre o tráfico de pessoas e o agenciamento sexual: brasileiras profissionais do sexo na Espanha". Oralidades, 9:189-219.

. 2014. "Turismo sexual, movilidades a través de las fronteras y trata de personas". Sexologia y Sociedad, 20:45-46.

POLLAK, Michael. 1985. "A homossexualidade masculina, ou: a felicidade do gueto?". In: P. Ariés \& A. Béjin (orgs.), Sexualidades Ocidentais. São Paulo: Brasiliense. pp. 54-76. 
RAGO, Luiza M. 1991. Os prazeres da noite: prostituição e códigos da sexualidade feminina em São Paulo. Rio de Janeiro: Paz e Terra.

RIOS, Roger R. 2006. "Para um direito democrático da sexualidade". Horizontes Antropológicos, 12(26):71-100.

- (org.). 2007. Em defesa dos direitos sexuais. Porto Alegre: Livraria do Advogado.

ROBINSON, Paul. 1977. The modernization of sex. New York: Harper.

RUBIN, Gayle. 1989. "Thinking sex: notes for a radical theory of the politics of sexuality". In: Carole Vance (ed.), Pleasure and danger: toward a politics of sexuality. Boston: Routlegde. pp. 267-319.

RUSSO, Jane A. 2002. "A difusão da psicanálise no Brasil na primeira metade do século XX — da vanguarda modernista à rádio-novela". Estudos e Pesquisas em Psicologia, 2(1):51-61.

- 2004. "Do desvio ao transtorno: a medicalização da sexualidade na nosografia psiquiátrica contemporânea". In: A. Piscitelli; M. F. Gregori \& S. Carrara, Sexualidade e saberes: convenções e fronteiras. Rio de Janeiro: Garamond. pp. 95-114.

. 2007. "Psychoanalysis in Brazil - institucionalization and dissemination among the lay public". Estudios Interdisciplinarios de America Latina y el Caribe, 18:63-80.

- 2009. "A sexologia na era dos direitos sexuais". In: Gilberto Velho \& Luiz F. D. Duarte (orgs.), Gerações, família, sexualidade. Rio de Janeiro: 7 Letras. pp. 63-76.

RUSSO, Jane A. \& CARRARA, Sérgio. 2002. "A psicanálise e a sexologia no Rio de Janeiro de entre-guerras: entre a ciência e a autoajuda". História, Ciências, Saúde - Manguinhos, 9(2):273-290.

SANTOS, Ailton da S. 2014. O gênero encarnado: modificações corporais e riscos à saúde de mulheres trans. Tese de Doutorado em Saúde Coletiva, UERJ.
SILVA, Claudio R. da. 1998. Reinventando o sonho: história oral de vida política e homossexualidade no Brasil Contemporâneo. Dissertação de Mestrado em História Social, Faculdade de Filosofia, Letras e Ciências Humanas, USP. SIMÕES, Júlio \& FACCHINI, Regina. 2009. Na trilha do arco-íris: do movimento homossexual ao LGBT. São Paulo: Perseu Abramo.

SIMÕES, Júlio \& CARRARA, Sérgio. 2014. "O campo de estudos socioantropológicos sobre diversidade sexual e de gênero no Brasil: ensaio sobre sujeitos, temas e abordagens". Cadernos Pagu (Unicamp) [no prelo].

STEPAN, Nancy L. 1990. "Eugenics in Brazil, 1917-1940". In: M. B. Adams (ed.), The wellborn science-eugenics in Germany, France, Brazil and Russia. New York: Oxford University Press. pp. 110-152.

. 1996. "The hour of eugenics" - race, gender and nation in Latin America, Ithaca e London. Ithaca: Cornell University Press.

TEIXEIRA, Flávia B. 2013. Dispositivos de dor: saberes poderes que (con) formam as transexualidades. São Paulo: Annablume/Fapesp.

VALE DE ALMEIDA, Miguel. 2009. “Ser mas não ser, eis a questão. O problema persistente do essencialismo estratégico". Working Paper CRIA 1, Lisboa. Mimeo.

VANCE, Carole. 1989. "Pleasure and danger: toward a politics of sexuality". In: __. (org.), Pleasure and danger: exploring female sexuality. London: Pandora Press. pp. 01-27. . 1995. "A antropologia redescobre a sexualidade: Um comentário teórico". Physis-Revista de Saúde Coletiva, 5(1):7-32.

VIANNA, Adriana de R. B. \& LACERDA, Paula. 2004. Direitos e políticas sexuais no Brasil: o panorama atual. Rio de Janeiro: Clam/IMS/Cepesq. 
VIANNA, Adriana de R. B. \& FARIAS, Juliana. 2011. "A guerra das mães: dor e política em situações de violência institucional". Cadernos Pagu, 37:79-116. WALKOWITZ, Judith R. 1983. Prostitution and Victorian society - women, class, and the state. New York: Cambridge University Press.

WEEKS, Jeffrey. 1985. Sexuality and its discontents: meanings, myths \& modern sexualities. London: Routlegde \& Kegan Paul.

_. 1989 [1981]. Sex, politics and society: the regulation of sexuality since 1800 . Londres/N.York: Longman.

WEISS DE JESUS, Fátima. 2010. "A cruz e o arco-íris: Refletindo sobre gênero e sexualidade a partir de uma 'igreja inclusiva' no Brasil". Ciencias Sociales y Religión, 12:131-146.

ZILLI, B. D. 2009. "BDSM de A a Z: a despatologização através do consentimento nos Manuais da Internet". In: M. E. D. Benítez \& Carlos E. Fígari (orgs.), Prazeres dissidentes. Rio de Janeiro: Garamond. pp. 481-508. 


\section{Resumo}

Neste artigo, discuto a hipótese de que a emergência da noção de direitos sexuais e a crescente utilização da linguagem dos direitos humanos para consolidar uma ampla agenda de reivindicações relativas aos prazeres, aos corpos e às práticas sexuais significam mais que o mero reconhecimento de que essa dimensão da experiência humana foi alvo da ingerência autoritária do Estado no passado, e de que precisa agora de proteção especial. Tendo como referência a já significativa literatura etnográfica brasileira sobre práticas, valores, identidades e intervenções públicas relativas à sexualidade, tomo a emergência da noção de direitos sexuais como aspecto central de um processo mais amplo de transformação que acontece no nível das políticas sexuais e que incide sobre o próprio dispositivo da sexualidade. Fruto da relação dinâmica entre diferentes atores sociais (ativistas, gestores públicos, políticos, juristas, pesquisadores etc.), tais direitos são aqui considerados como símbolo da emergência histórica de um "novo" regime secular da sexualidade, acompanhado por um estilo de regulação moral que lhe é próprio.

Palavras-chave Sexualidade, Política sexual, Direitos sexuais, Brasil.

\section{Abstract}

In this article, I discuss the hypothesis that the emergence of the concept of sexual rights, alongside an increase in the use of the language of human rights in social claims relating to pleasure, bodies and sexual practices, signal more than the mere recognition of the fact that this dimension of human experience was the target of authoritarian intrusions by the state in the past and that it now merits special protection. Based on the already significant Brazilian ethnographic literature on practices, values, identities and public interventions related to sexuality, I analyse the emergence of the concept of sexual rights as a central aspect within a wider process of transformation at the level of sexual politics - one which changes, in crucial aspects, the device of sexuality itself. As the result of the dynamic relationship between different social actors (activists, policy makers, politicians, lawyers, researchers etc.), these rights are here considered a symbol of the historical emergence of a "new" secular regime of sexuality, accompanied by a moral regulatory style of its own.

Key words Sexuality, Sexual politics, Sexual rights, Brazil. 